\title{
Erratum zu: Third Culture Building: Vom territorialen Paradigma zur Vereinbarungskultur
}

Jürgen Beneke

\section{Erratum zu:}

\section{Kapitel 4 in: H. W. Giessen und C. Rink (Hrsg.), Migration, Diversität und kulturelle Identitäten, https://doi.org/10.1007/978-3-476-04372-6_4}

Im 4. Kapitel, des Buches von Giessen und Rink „Migration, Diversität und kulturelle Identitäten“"wurden Korrekturen gegenüber der ersten Veröffentlichung ausgeführt.

Die E-Mail Adresse des Autors Jürgen Beneke war in der ersten Version leider falsch wiedergegeben und wurde in dieser Version nun richtig eingefügt.

Die Literatur am Ende des Kapitels war unvollständig und wurde nun vervollständigt. 